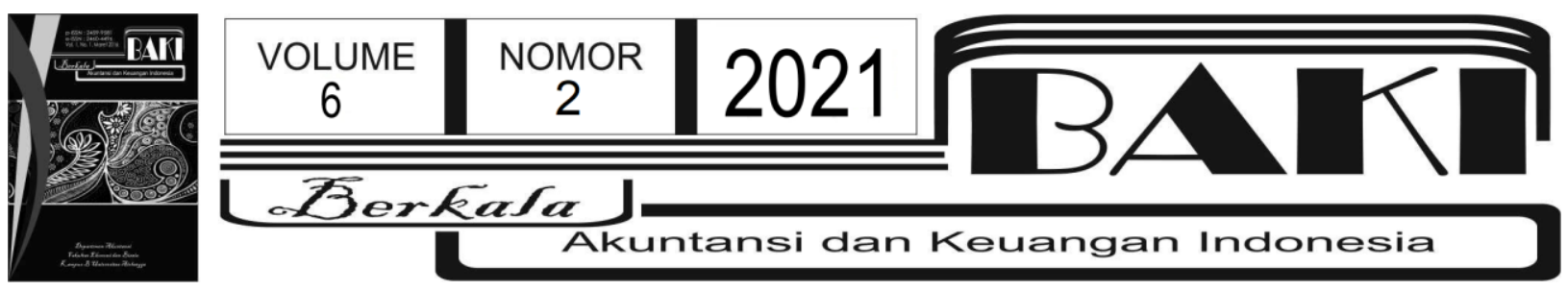

\title{
THE EFFECT OF FREE FLOAT RATIO AND PROFITABILITY ON STOCK PRICE
}

\section{PENGARUH RASIO FREE FLOAT DAN PROFITABILTAS TERHADAP HARGA SAHAM}

\author{
Wiharti Arum Sari ${ }^{1 *(D)}$, Arif Nugroho Rachman² \\ 1,2STIE Surakarta \\ *corresponding author: arum08ws@gmail.com
}

INFO ARTIKEL

Histori Artikel:

Tanggal Masuk 16 Februari 2021

Revisi Diterima 27 Maret 2021

Tanggal Diterima 30 Agustus 2021

Tersedia Online 6 September 2021

Keywords: EPS, Free Float, Profitability Ratio, ROA, ROE, Stock Price

\section{A BSTRACT}

The Indonesian Stock Exchange in supporting and increasing the confidence of stock investors, it is deemed necessary to apply the Free Float as an adaptation to the market capacity used in calculating the LQ45 and IDX30 Indices in 2019. Free float is the total shares whose ownership is less than $5 \%$ based on data from PT Kustodion Sentral Indonesian Securities. Changes in LQ45 and IDX30 Index Methodology were announced by the IDX in the announcement letter attached to the IDX website with IDX letter number No: Pebng-00893 / BELOPP / 11-2018 dated 23 November 2018). The discussion in this research is whether share prices can be affected by, Free float ratios, and profitability ratios which include ROE, ROA and EPS in companies listed on the LQ45 index for the period 2015-2019. The population in this research is the corporations listed on the LQ45 index. The sample collection technique used purposive sampling, with a total of 19 companies. Multiple linear regression analysis is used by researchers as an analytical tool. Multiple linear regression analysis shows that the stock price $(Y)$ is not affected by the free float ratio $(X 1)$ and ROA (X3). ROE (X3) affects the stock price (Y) negatively, while the stock price is positively affected by EPS (X4). The results in the determination coefficient table, the adjusted $R^{2}$ value is 0.633 , so that the dependent variable, namely the stock price, is simultaneously affected by the independent variables, namely the Free Float Ratio, ROE, ROA and EPS with a value of $63.3 \%$, while $36.7 \%$ is affected by the variables in outside of this research.

Kata Kunci: EPS, Free Float, Harga Saham, Rasio Profitabilitas, ROA, ROE
ABSTRAK

Bursa Efek Indonesia dalam mendukung dan meningkatkan kepercayaan penanam saham, dirasa perlu menerapkan Free Float sebagai adaptasi atas kapasitas market yang dipakai dalam 
memperhitungkan Indeks LQ45 dan IDX30 pada tahun 2019. Free float ialah total saham yang kepemilikannya kurang dari $5 \%$ berdasarkan data dari PT Kustodion Sentral Efek Indonesia. Perubahan Metedologi Indeks LQ45 dan IDX30 diumumkan oleh BEI pada surat pengumuman yang terlampir dalam website IDX dengan nomor surat BEI No: Pebng-00893/BELOPP/11-2018 tanggal 23 November 2018). Pembahasan pada riset ini adalah apakah harga saham dapat dipengaruhi oleh, Rasio free float, dan Rasio Profitabilitias yang meliputi ROE, ROA, dan EPS di perusahaan yang tercatat pada indeks LQ45 periode tahun 2015-2019. Populasi pada riset ini yaitu corporation yang tercatat pada indeks LQ45. Tehnik pengumpulan sampel menggunakan Purposive Sampling, dengan jumlah 19 perusahaan. Analisis regresi linear berganda dipakai oleh peneliti sebagai alat analisis. Analisis regresi linier berganda menghasilkan bahwa harga saham $(\mathrm{Y})$ tidak terpengaruh oleh Rasio free float (X1) dan ROA (X3). ROE (X3) mempengaruhi harga saham (Y) secara negative, sedangkan Harga saham terpengaruh positif oleh EPS (X4). Hasil pada tabel koefisien determinasi, nilai adjusted $R^{2}$ yaitu 0,633 , sehingga variabel dependen yaitu stock price terpengaruh secara bersamaan oleh variabel independen yaitu Ratio Free Float, ROE, ROA dan EPS dengan nilai $63,3 \%$, sedangkan $36,7 \%$ terpengaruh oleh variabel di luar dari riset ini.

Berkala Akuntansi dan Keuangan Indonesia p-ISSN: 2459-9581; e-ISSN 2460-4496

DOI: 10.20473/baki.v6i2.25500

Open access under Creative Common Attribution-Non Commercial-Share A like 4.0 International Licence

(CC-BY-NC-SA) @(1) @ (0) 


\section{Pendahuluan}

Era globalisasi, perekonomian dunia mengalami persaingan yang cukup ketat dan pertumbuhan yang pesat. Perusahaan akan bertahan dan berkembang memerlukan dana yang cukup besar sebagai modal usaha. Pasar modal mempunyai peranan yang penting, cara alternatif untuk mendapatkan sumber dana. Pasar modal memiliki fungsi yaitu menemukan perusahaan yang memerlukan modal dengan pihak yang menginvestasikan modal ke Bursa Efek Indonesia (BEI) di pasar modal. Perusahaan berlomba untuk mendaftar sebagai emiten di BEI. BEI sebagai wadah informasi untuk para pelaku saham memiliki syarat dan ketentuan yang berlaku. BEI mencatat perusahaan perusahaan besar yang memiliki tingkat likuiditas terbaik dengan kategori LQ45 (website idx).

Perusahaan yang terdaftar pada LQ45 adalah 45 perusahaan yang memenuhi kategori yang dimiliki BEI sebagai perusahaan terbaik di Indonesia. Perusahaan yang tercatat di LQ45 tentunya menjadi minat para investor untuk menginvetasikan dana ke perusahaan tersebut. Investor apabila ingin melakukan akitivitas di pasar modal harus memperhatikan harga saham, sebagai tolak ukur perusahaan. Harga saham meningkat, berpotensi kinerja perusahaan dan semakin besar pendapatan yang diperoleh perusahaan (Darmadji, 2011). Harga saham memiliki sifat fluktuatif, untuk itu investor perlu mencari informasi mengenai pasar saham. Informasi pasar saham sangat berperan penting, sebagai daya tarik investor melakukan aktivitas di pasar modal. Informasi dapat mendorong ekspektasi investor untuk mengambil keputusan akan berinvestasi ke perusahaan mana.

Bursa Efek Indonesia dalam mendukung dan meningkatkan kepercayaan penanam saham, dirasa perlu menerapkan Free Float sebagai adaptasi atas kapasitas market yang dipakai dalam memperhitungkan Indeks LQ45 dan IDX30 pada tahun 2019. Free float ialah total saham yang kepemilikannya kurang dari $5 \%$ berdasarkan data dari PT Kustodion Sentral Efek Indonesia (idx.co.id). Indeks LQ45 yaitu peniliaian performa perusahaan dari kapasitas paling likuiditas. BEI menerapkan free float sebagai penilian indeks disebabkan keadaan pasar sesungguhnya, dimana banyak perusahaan besar yang terdata dalam bentuk warkat (scrip) atau dimiliki investor strategis yang mempunyai motif mempertahankan kepemilikannya dalam jangka panjang. Perubahan Metodelogi Indeks LQ45 dan IDX30 diumumkan oleh BEI pada surat pengumuman yang terlampir dalam website IDX dengan nomor surat BEI No: Pebng00893/BELOPP/11-2018 tanggal 23 November 2018). Ketentuan baru BEI mengenai rasio free float, dan memberikan insentife bagi emiten yang memiliki free float $40 \%$ mendapatkan potongan PPH badan sebesar $3 \%$, menjadikan emiten segera menaikkan rasio free float agar mendapatkan insentif tersebut (cnbcindonesia.com). 
Dua cara Rasio Float mempengaruhi harga saham. Pertama Rasio Float apabila mengembang rendah, investor akan menghindar. Kedua apabila rasio float rendah, berarti jumlah saham di pasar tidak cukup dan likuiditas rendah (Bostanci \& Kilic, 2010) . Kebijakan baru BEI memerlukan pengujian mengenai pengaruh free float pada harga saham. Khususnya perusahaan tercatat sebagai LQ45. Harga saham dapat terpengaruh oleh berbagai faktor rasio profitabilitas diantaranya EPS, ROA, ROE (Bodie, 2014). Analisis pendekatan yang sering dilakukan mengunakan Analisis Fundamental. Analisis fundamental ialah analisis yang menetukan value yang dihasilkan oleh perusahaan dengan melihat kemajuan perekonomi negara, lingkungan bisnis perusahaan dalam menemukan harga saham yang normal (Bodie, 2014).

Earning per share bagian dari hasil perusahaan yang dipergunakan bagi persaham beredar atas laba perlembar saham menjadi parameter dari daya laba suatu corporasi (Bansal, 2014). EPS tinggi menjadikan harga saham naik. Harga saham dapat dipengaruhi oleh EPS, ROE sedangkan Suku Bunga SBI, Inflansi dan DER tidak mempengaruhi harga saham (Ira Roshita Dewi \& Sri Artini, 2016). Harga saham tidak terpengaruh oleh EPS dan DPS (Khairani, 2016). ROA dan EPS berpengaruh postif signifikan sedangkan ROE tidak berpengaruh pada harga saham (Santy \& Triyonowati, 2017). ROA, NPM, EPS secera simulutan dan persial mempengaruhi signifikan pada harga saham (Watung \& llat, 2016) . ROA menggambarkan keberhasilan perusahaan dalam memperoleh laba dari penggunaan aktiva. Apabila nilai ROA besar, perusahaan memiliki peluang untuk meningkatkan pertumbuhan akan efektif dalam menghasilkan laba. ROE yang lebih tinggi menjadikan harga saham akan meningkat, apabila lebih rendah ROEnya maka harga saham akan menurun.

Tujuan riset ini adalah menguji apakah rasio free float, ROA, ROE, dan EPS dapat memicu perubahan harga saham, ROE dapat mempengaruhi harga saham pada perusahaan pada Index LQ45 di BEI masa 2015-2019. Hasil penelitian ini diharapkan dapat menjadi rujukan tambahan bagi penelitian selanjutnya khususnya yang meneliti mengenai hal tersebut.

Bagian dari artikel ini selanjutnya akan memaparkan tinjauan pustaka, metode penelitian, hasil dan pembahasan, serta simpulan, saran, dan keterbatasan.

\section{Tinjauan Pustaka}

\subsection{Analisis Laporan Keuangan}

Analisis laporan keuangan yaitu prosedur pembedahan informasi keuangan dan mempelajari setiap unsurnya sebagai fungsi mendapatkan pemahaman dan maksud yang baik dari laporan keuangan. Analisis Laporan keuangan dipakai untuk acuan penting pengukuran kesehatan keuangan perusahaan (Hery, 2015). Perhitungan dan interpretasi rasio keuangan 
merupakan kegiatan analisis laporan keuangan yang menghasilkan informasi terperinci perihal kinerja yang diraih suatu perusahaan dan permasalah yang terjadi di perusahaan (Nino et al., 2016). Pihak yang memerlukan laporan keuangan biasanya menggunakan dua atau lebih periode laporan keuangan sebagai perbandingan untuk pengambilan keputusan.

\subsection{Analisis Rasio}

Analsis rasio ialah gambaran analisis dipakai untuk menganalisis laporan keuangan, Rasio dijumlah dari laporan keuangan yang berisi atas income statment and financial position. Rasio keuangan ialah aktivitas perbandingan antar nilai yang terkandung dalam laporan keuangan menggunakan cara pembagian angka satu dengan angka yang lain (KAMSIR, 2013).

\subsection{Pasar Modal}

Pasar modal merupakan sarana untuk pengajuan serta permohonan atas bagian keuangan jangka panjang, biasanya diatas satu tahun. Pasar modal ialah aktivitas yang kaitannya dengan negosiasi umum serta jual beli efek, emiten yang berkaitan dengan saham yang diterbitkan, serta badan profesi yang bersangkutan dengan efek (Samsul, 2006). Pasar efek Indonesia dimaksud pasar elemen keuangan (sekuritas) jangka panjang yang diperdagangkan, berupa obligasi, saham, reksadana, elemen derivative yang dicetak oleh fiskus atau swasta yang bertempat di Indonesia.

Pasar modal memiliki fungsi sebagai intermediaries, yang berperan dalam mendukung ekonomi negara, sebagai penghubung antara emiten dan pemodal. Capital market mampu mendukung terbentuknya penggunaan dana yang efisien dan efektif, dengan begitu pemodal mampu menentukan menginvestasikan pada nilai return teroptimal (Tandelilin, 2010) .

\subsection{Saham}

Saham sebagai bukti pemilik perorangan atau lembaga pada corporasi atau Perseroan Terbatas (PT). Bentuk saham yaitu portofolio perenyataan pemilik portofolio terkait merupakan pemilik perusahaan emiten. Hak kepemilikan ditetapkan dari banyaknya penyertaan yang dimasukkan di perusahaan emiten. Saham ialah lembar kepemilikan sebagai modal di perusahaan emiten. Saham ialah unsur kepemilikan pada perusahaan emiten, dimana perlembarnya sebagai hak satu suara bagi pemodal (Bodie, 2014).

\subsection{Harga Saham}

Harga saham adalah nominal dibentuk di capital market saat periode khusus, harga saham bersifat fluktuatif secara cepat. Hal itu disebabkan oleh permintaan dan penawaran saham di capital market. 


\subsection{Rasio free float}

Free float diartikan sebagai selisih antar saham beredar dengan saham yang dibatasi dari akivitas capital market (Suwandi, 2020). Float Ratio menyatakan jumlah saham yang tersedia untuk public. Saham yang terbatas dari perdagangan disebut kepemilikan saham yang stabil, dan termasuk kepemilikan saham induk sebagai penyetir anak perusahaan, saham yang dipegang oleh pemerintah, dan kepemilikan silang antar perusahaan. Rasio saham yang dapat diperdagangkan, atau free float dapat memengaruhi perusahaan tata kelola, secara langsung atau tidak langsung via pasar karena mencerminkan kontrol perusahaan (Suwandi, 2020).

Dari definisi di atas, bisa disimpulkan untuk rumus Rasio Free Float:

$$
\text { Rasio Free Float }=\frac{\text { Saham kepemilikan publik (kepemilikannya dibawah 5\%) }}{\text { Jumlah saham beredar }} \times 100 \%
$$

\subsection{Rasio Profitabilitas}

Rasio profitabilitas ialah rasio pengukuran keberhasilan perusahaan untuk memperoleh keuntungan (Bodie, 2014). ROE, ROA dan EPS sebagai pengukuran keefektivitasan pengelola suatu perusahaan (Bodie, 2014). Perhitungan rasio profitabilitas bisa dengan membandingkan antar elemen di informasi keuangan, terpenting informasi keuangan neraca dan informasi laba/rugi. Penilaian rasio ini bertujuan bakal melihat pertumbuhan perusahaan pada rentang periode. Fluktuasi rasio profitabilitas (ROA, ROE, EPS) dapat mengetahui penyebab perubahan harga saham. Akibat dari pengukuran bisa sebagai evaluasi performa manajemen selama ini.

\subsection{Return on Equity (ROE)}

ROE yaitu rasio pengambaran besarnya peran serta modal untuk mewujudkan laba setelah pajak pajak (Hery, 2015). Rumus ROE adalah (Fahmi, 2012):

$$
\text { ROE }=\frac{\text { Laba bersih setelah pajak }}{\text { Total ekwitas }} \times 100 \%
$$

\subsection{Return On Asset (ROA)}

Return On Assets mengambarkan berapa besar asset yang dimiliki perusahaan untuk menghasilkan laba bersih (Hery, 2015). ROA sebagai bahan evaluasi oleh manajemen perusahaan atas keefektivitas dan keefisiensian atas pengelolaan seluruh aktiva perusahaan (Dendawijaya, 2013). Ditentukan rumus ROA yaitu :

$$
\text { ROA }=\frac{\text { Laba bersih setelah pajak }}{\text { Total aktiva }} \times 100 \%
$$




\subsection{Earning Per Share (EPS)}

Earning Per Share yaitu wujud dari keuntungan yang dibagikan ke pemilik saham perlembarnya(Fahmi, 2012). Rumus EPS yaitu :

$$
E P S=\frac{\text { Laba bersih setelah pajak }}{\text { Jumlah saham beredar }}
$$

EPS unsur dari laba perusahaan yang diperuntukkan pada setiap saham yang beredar dari saham publik, EPS seperti indikator dari profitabilitas suatu perusahaan (Bansal, 2014). Nilai EPS apabila tinggi menjadikan harga saham tinggi(Egam et al., 2017), berbanding terbalik dengan penelitian yang dilakukan oleh (Khairani, 2016) yang menghasilkan harga saham tidak dipengaruhi oleh EPS dan DPS (Khairani, 2016). Apabila semakin besar ROA, perusahaan memiliki peluang untuk meningkatkan pertumbuhan akan efektif dalam menghasilkan laba. ROE yang lebih tinggi menjadikan harga saham akan meningkat, apabila lebih rendah ROEnya maka harga saham akan menurun (MUSSALAMAH, 2017).

\subsection{Hipotesis}

Dua cara Rasio Float mempengaruhi harga saham. Pertama Rasio Float apabila mengembang rendah, investor akan menghindar. Kedua apabila rasio float rendah, berarti jumlah saham di pasar tidak cukup dan likuiditas rendah (Bostanci \& Kilic, 2010), hal ini diperkuat dengan riset (Suwandi, 2020) yang menjelaskan bahwasannya harga saham dipengaruhi secara oleh saham free float.

\section{H1: Rasio free float memiliki pengaruh positif pada harga saham.}

ROE dipakai sebagai alat ukur perusahaan dalam mendapatkan keuntungan untuk investor. ROE dinilai dapat mempresentasikan keberhasilan pemegang saham (Subramanyam, 2017). Persentase ROE yang tinggi memperlihatkan performa corporasi emiten lebih baik pada pengelolaan modal yang ada untuk mendapatkan keuntungan. (Ira Roshita Dewi \& Sri Artini, 2016) menyebutkan kenaikan presentase ROE sehingga harga saham corporasi terkait terjadi peningkatan. Nilai ROE yang mengalami kenaikan, menambah efisien pemakaian modal pribadi yang dilakukan perusahaan agar mendapatkan keuntungan untuk pemilik saham (Ira Roshita Dewi \& Sri Artini, 2016) . ROE mampu mempengarui secara positif signifikan pada harga saham. Hal tersebut membuktikan bahwa nilai ROE yang semakin tinggi maka memiliki dampak pada kenaikan harga saham (Santy \& Triyonowati, 2017).

H2: ROE mempunyai pengaruh positif pada harga saham. 
Rasio ini mengambarkan seberapa besar asset yang dimiliki perusahaan untuk menghasilkan laba bersih. (Dendawijaya, 2013) menyatakan ROA sebagai bahan evaluasi oleh manajemen perusahaan atas keefektivitas dan keefisiensian atas pengelolaan seluruh aktiva perusahaan. Nilai ROA yang tinggi, maka perusahaan dapat dikatakan efisien apabila kesamaan jumlah aktiva, namun dapat mendapatkan keuntungan yang bertambah, begitupun sebaliknya. Akhirnya mempengaruhi pembeli untuk dapat tertarik dalam membeli saham pada perusahaan, hal tersebut diperkuat dengan peneltian (Santy \& Triyonowati, 2017) bahwa ROA berpengaruh postif signifikan sedangkan ROE tidak berpengaruh pada harga saham.

\section{H3: ROA mempunyai pengaruh positif pada harga saham.}

Menurut (Darmadji, 2011), rasio EPS memperlihatkan besarnya laba per lembar saham untuk investor. Nilai EPS tinggi, sebagai berita baik bagi investor. Hal itu menjadikan daya tarik pemodal untuk menginvetasikan pada saham corporasi terkait. Nilai EPS apabila meningkat, dapat memicu daya tarik investor untuk membeli saham di corporasi terkait, kemudian harga saham mengalami peningkatan akibat tingginya permintaan. Hal tersebut diperkuat dengan peneltian yang lalu oleh(Egam et al., 2017), (Ira Roshita Dewi \& Sri Artini, 2016) , (Santy \& Triyonowati, 2017), dan (Rahmadewi \& Abundanti, 2018) yang menghasilkan bahwa EPS mampu mempengaaruhi postif signifikan pada harga saham.

\section{H4: EPS mempunyai pengaruh positif pada harga saham.}

Model riset pengaruh rasio free float dan profitabilitas terhadap harga saham ditunjukkan pada gambar berikut:

\section{Gambar 1}

Kerangka Pemikiran

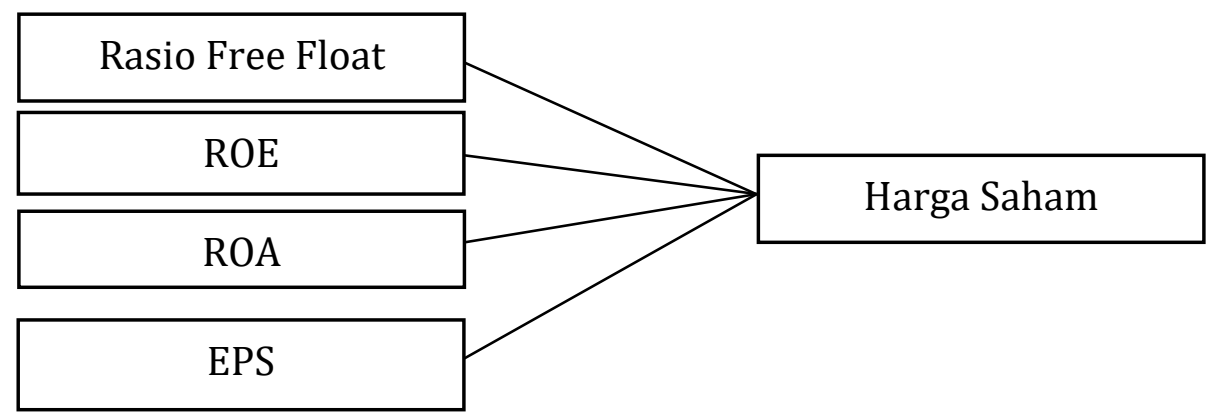

\section{Metodologi Penelitian}

\subsection{Jenis penelitian}

Riset ini memakai kuantitatif. Riset kuantitatif ialah cara yang dipakai dalam pengujian beberapa teori khusus dengan memeriksa keberkaitan antar variable (Noor, 2011). Variabel terkait dinilai (memakai instrument riset) hingga menghasilkan data angka yang bisa dikaji sesuai aturan statistik. Riset ini bersifat deskriptif explanatory. Riset explanatory ialah riset yang 
bertujuan menerangkan posisi beberapa variabel yang diperiksa dan keberkaitannya antara variabel tersebut (SUGIYONO, 2013).

\subsection{Populasi (Objek) Penelitian}

Populasi penelitian ini meliputi corporasi tercatat sebagai LQ45 di BEI 2015-2019. Populasi ialah area umum meliputi obyek atau subyek berkualitas dan berkarakteristik khusus sesuai ketentuan peneliti agar dianalisa dan selanjutnya diambil kesimpulannya (SUGIYONO, 2013).

\subsection{Teknik Pengambilan Sampel}

Sampel ialah unsur dari beberapa karakteristik populasi (SUGIYONO, 2013). Teknik yang dipakai ialah purposive sampling. Purposive sampling, dipakai peneliti apabila peneliti memiliki beberapa kriteria tertentu pada pengambilan sampelnya (Arikunto, 2007). Sesuai ketentuan pemilihan sampel, hingga didapat sampel sebesar 19 dikali 5 tahun obesrvasi, dan terdapat data outlier sebanyak 8 sampel dikali 5 tahun, maka hasil akhir observasi penelitian menjadi 55 objek penelitian.

Tabel 3.1.

Prosedur Pemilihan Sampel

\begin{tabular}{|c|l|c|}
\hline No. & \multicolumn{1}{|c|}{ Keterangan } & Jumlah \\
\hline 1 & $\begin{array}{l}\text { Corporasi indeks LQ45 yang tercatat di BEI pada tahun 2015- } \\
2019\end{array}$ & 45 \\
\hline 2 & $\begin{array}{l}\text { Corporasi yang tidak terdaftar sebanyak 10 kali berkelanjutan di } \\
\text { daftar LQ45 BEl periode 2015-2019 }\end{array}$ & $(22)$ \\
\hline 3 & $\begin{array}{l}\text { Corporasi indeks LQ45 yang tidak memilki kelengkapan data } \\
\text { pada tahun 2015-2019 }\end{array}$ & $(2)$ \\
\hline 4 & $\begin{array}{l}\text { Perusahaan indeks LQ45 yang mengalami kerugian pada tahun } \\
2015-2019 \text { (pada tahun 2019 mengalami kerugian) }\end{array}$ & $(2)$ \\
\hline 5 & Jumlah perusahaan & 19 \\
\hline 6 & Jumlah observasi awal (19 x 5) & 95 \\
\hline 7 & $\begin{array}{l}\text { Data Outlier (datanya yang menyimpang terlalu jauh antar } \\
\text { variabel X) }\end{array}$ & 40 \\
\hline 8 & Jumlah observasi akhir (11 x 5) & 55 \\
\hline
\end{tabular}

\subsection{Teknik Pengumpulan Data}

Teknik pengumpulan file yang dipakai ialah file sekunder yaitu rangkuman file informasi keuangan yang didapat dari BEl. File yang dipakai ialah file kuantitatif, ialah susunan angka pada suatu laporan maupun dokumentasi. Data tersebut meliputi laporan keuangan yang diambil dari BEI 2015-2019. Teknik dokumentasi digunakan peneliti sebagai teknik pengumpulan data dengan menyimpan tiap transaksi atau berkas yang dibutuhkan dengan cara 
membaca, mengamati, menganalisa dan mengambil atas informasi keuangan perusahaan. Dokumen ialah fakta penting dan data disimpan pada bahan yang berwujud dokumentasi. File yang ada diantaranya letter, daily report, etc (Noor, 2011) .

\subsection{Variabel}

Variabel dalam riset ini terbagi atas dua jenis, variabel bebas serta variabel terikat. Variabel independen (bebas) pada riset ini meliputi rasio free float, ROA, ROE, EPS. Harga saham sebagai variable dependen.

\subsubsection{Variabel Independen}

1. Rasio free float

Free float diartikan sebagai selisih antar saham beredar dengan saham yang dibatasi dari akivitas capital market. Free float ialah total saham yang kepemilikannya kurang dari 5\% berdasarkan data dari PT Kustodion Sentral Efek Indonesia (idx.co.id). Rasio float menyatakan jumlah saham yang tersedia untuk umum.

Bisa disimpulkan untuk rumus rasio free float :

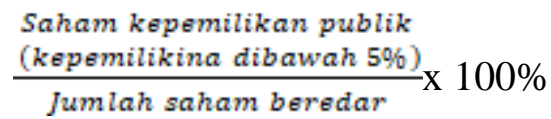

\section{Return on Equity (ROE)}

Rasio yang menggambarkan keberhasilan corporasi untuk memperoleh keuntungan dengan modal pribadi perusahaan. Kenaikan presentase ROE menjadikan harga saham corporasi terkait juga meningkat. Nilai ROE yang mengalami kenaikan, menambah efisien pemakaian modal pribadi yang dilakukan perusahaan agar mendapatkan keuntungan untuk pemilik saham. Rasio sebagai tolak ukur kefektifitasan dan kefesiensian dalam pengelolan modal pribadi yang dikerjakan pihak manajemen perusahaan. ROE yang mengalami kenaikan menggambarkan keberhasilan corporasi untuk memperoleh keuntunngan besar untuk pemilik saham. Perusahaan yang memiliki kemampuan dalam memberikan keuntungan untuk pemilik saham, sehingga saham tersebut semakin menarik untuk dibeli, karena hal tersebut maka ROE dapat memberi pengaruh pada perubahan harga saham(Ira Roshita Dewi \& Sri Artini, 2016). Bisa disimpulkan untuk rumus

$$
\mathrm{ROE}=\frac{\text { Laba bersih setelah pajak }}{\text { Total ekwitas }} \times 100 \%
$$




\section{Return on Asset (ROA)}

Rasio yang menggambarkan keberhasilan corporasi dalam memakai semua aktiva yang dimiliki untuk mendapatkan keuntungan bersih. ROA sebagai alat evaluasi keefektivitasan dan keefesiensian manajemen perusahaan untuk mengatur semua aktiva perusahaan (Ira Roshita Dewi \& Sri Artini, 2016). Bisa disimpulkan untuk rumus ROA

$$
\text { ROA }=\frac{\text { Laba bersih setelah pajak }}{\text { Total aset }} \times 100 \%
$$

\section{4. $\quad$ Earning per Share (EPS)}

EPS ialah cara mengindikasi prestasi perusahaan untuk mewujudkan keuntungan bagi investor, nilai EPS sebagai indikator kemampuan perusahaan untuk memperoleh laba bersih perlembar saham suatu perusahaan (Ira Roshita Dewi \& Sri Artini, 2016).

Bisa disimpulkan untuk rumus EPS adalah:

$$
\text { EPS }=\frac{\text { Laba bersih setelah pajak }}{\text { Jumlah saham beredar }}
$$

\subsubsection{Variabel Dependen}

\section{Harga Saham}

Harga saham ialah harga lembaran saham setiap corporasi LQ45 yang terdaftar di BEI 2015-2019. Harga saham yang dipakai pada riset ini ialah harga saham penutupan akhir tahun, waktu tutup buku.

\subsection{Teknik Analisis}

Teknik analisis data yang dipakai pada riset ini ialah analisis regresi linier berganda. Analisis regresi berganda sebagai alat ukur pengaruh atau keberkaitan variabel independen dengan variabel dependen. Model persamaan regresi berganda yang dipakai adalah:

$$
\begin{aligned}
& \mathrm{HS}=\alpha+\beta_{1} \mathrm{FFR}+\beta_{2} \mathrm{ROE}+\beta_{3} \mathrm{ROA}+\beta_{4} \mathrm{EPS}+\mathrm{e} \\
& \text { Keterangan : } \\
& \mathrm{HS} \quad=\text { Harga saham } \\
& \alpha \quad=\text { Konstanta } \\
& \begin{array}{ll}
\alpha 1, \beta 2, \beta 3 \quad=\text { Koefesien regresi } \\
\text { FFR } & =\text { Rasio free float } \\
\mathrm{ROA} & =\text { Return on asset } \\
\mathrm{ROE} & =\text { Return on equity } \\
\mathrm{EPS} & =\text { Earning per share } \\
\mathrm{e} & =\text { faktor error }
\end{array}
\end{aligned}
$$




\section{Hasil dan Pembahasan}

\subsection{Hasil}

Objek riset yang dipakai untuk dalam riset ini ialah corporasi yang tercatat sebagai indeks LQ45 di BEI 2015 - 2019. Sampel yang dipakai pada riset ini adalah 11 corporasi pada LQ45 yang menggunakan ketentuan peneliti.

Tabel 4.1

Hasil Statistik Deskriptif

\begin{tabular}{lccccc}
\hline & N & Minimum & Maksimum & Mean & Std. Deviasi \\
\hline HARGA SAHAM $(Y)$ & 55 & 1255 & 22325 & 6063,73 & 5147,752 \\
RASIO FREE FLOAT $\left(X_{1}\right)$ & 55 & 30,00 & 49,93 & 42,7631 & 6,58609 \\
ROE $\left(X_{2}\right)$ & 55 & 1,00 & 29,20 & 14,1451 & 5,08185 \\
ROA $\left(X_{3}\right)$ & 55 & 0,13 & 16,50 & 6,5862 & 4,52082 \\
EPS $\left(X_{4}\right)$ & 55 & 20,00 & 1183,48 & 359,2089 & 261,76274
\end{tabular}

Sumber : data yang telah diolah oleh peneliti, 2021

Tabel 4.3

Hasil Analisis Regresi Linier Berganda

\begin{tabular}{|c|c|c|c|c|}
\hline Variabel & Koefisien & $t_{\text {hitung }}$ & Sig. & Kesimpulan \\
\hline (Constant) & 786,982 & 0,214 & 0,831 & \\
\hline Rasio Free Float $\left(\mathrm{X}_{1}\right)$ & 77,995 & 0,890 & 0,378 & $\begin{array}{l}\text { Tidak } \\
\text { Berpengaruh }\end{array}$ \\
\hline $\operatorname{ROE}\left(\mathrm{X}_{2}\right)$ & $-344,989$ & $-3,427$ & 0,001 & Berpengaruh \\
\hline $\mathrm{ROA}\left(\mathrm{X}_{3}\right)$ & 217,093 & $-1,526$ & 0,133 & $\begin{array}{l}\text { Tidak } \\
\text { Berpengaruh }\end{array}$ \\
\hline EPS $\left(X_{4}\right)$ & 15,009 & 8,742 & 0,000 & Berpengaruh \\
\hline
\end{tabular}

Sumber : SPSS20, (diolah penulis, 2021)

Persamaan regresi linier berganda sebagai berikut:

$\mathrm{HS}=786,982+77,995 \mathrm{RFF}-344,989 \mathrm{ROE}+217,093 \mathrm{ROA}+15,009 \mathrm{EPS}+\mathrm{e}$

Uji F dipakai agar mengetahui layak tidaknya antara variabel bebas, apakah mempengaruhi signifikan secara simultan pada variabel berikut. Kriteria penguji yaitu tingkat signifikan < 0,05. Hasil uji $F$ diperoleh nilai $F$ signifikansi pada $0,000<0,05$ yang memperlihatkan bahwasanya variabel bebas (Rasio free float, ROE, ROA, dan EPS) yang dipakai pada riset ini secara simultan memicu perubahan harga saham.

Uji Koefisien determinasi (R2) sebagai alat ukur kapasitas model untuk menerangkan variance variabel dependen. Nilai koefisien determinasi yaitu antara nol dan satu. Nilai R2 yang kecil maka kemampuan semua variabel independen guna menerangkan variance variabel dependen sangat terbatas. Nilai yang dekat dengan satu berarti semua variabel independen, hampir semua memberi informasi yang diperlukan untuk memprediksi variance variabel dependen (Ghozali, 2016). Hasil analisis diketahui bahwa nilai Adjusted R2 sebesar 0,633 atau sama dengan 63,3\%. Angka tersebut mengandung arti bahwa variabel Rasio free float (X1), ROE (X2), ROA (X3), dan EPS (X4) secara simultan mampu memicu perubahan variabel harga saham (Y) sebesar $63,3 \%$, sedangkan $36,7 \%$ dipengaruhi oleh selain variabel tersebut. 
Uji t dipakai agar mengetahuii pengaruh antar variabel bebas apakah signifikan secara terpisah pada variabel terikat (harga saham). Besaran signifikan $\alpha=0.05$. Nilai sig $t>0.05$, maka variabel bebas memberikan pengaruh tidak signifikan pada variabel terikat. Nilai sig $\mathrm{t}<$ 0.05 , variabel bebas mempengaruhi secara signifikan pada variabel terikat. Tabel.2 dapat diketahui bahwa variabel ROE (X2), EPS (X4), mampu memicu secara signifikan pada perubahan harga saham, namun Rasio free float (X1) serta ROA (X3) tidak memicu pengaruh secara signifikan pada harga saham.

\subsection{Pembahasan}

\subsubsection{Pengaruh Rasio free float Terhadap Harga Saham}

Hasil riset dapat dilihat pada tabel 4. yang memperlihatkan bahwasanya nilai signifikansi sebesar 0,378 > 0,05 serta besaran koefisien -77,995 hal ini memperlihatkan bahwasanya Rasio free float tidak mampu memicu pada perubahan harga saham. Riset ini berbanding terbalik dengan riset (Suwandi, 2020). Harga saham dapat berubah disebabkan oleh faktor eksternal, yang diantaranya adanya pengaruh politik dan pandemi yang melanda dunia diawal tahun 2019 (Covid-19).

\subsubsection{Pengaruh ROE Terhadap Harga Saham}

Hasil riset bisa dilihat pada tabel 5. yang memperlihatkan bahwa nilai signikansi sebesar $0,001<0,05$ dengan nilai koefisien sebesar -344,989 berarti mempunyai hubungan negative dengan harga saham. Riset ini sesuai dengan riset (Santy \& Triyonowati, 2017) yang menyebutkan bahwa harga saham dipengaruhi secara tidak signifikan oleh ROE. Apabila nilai ROE besar mengakibatkan harga saham semakin rendah, karena kepercayaan investor terhadap perusahaan semakin berkurang.

\subsubsection{Pengaruh Return On Assets terhadap Harga Saham}

Hasil riset dapat dilihat pada tabel 4. yang menunjukkan bahwa nilai besaran signikansi $0,133>0,05$ serta nilai koefisien 217,093 berarti ROA tidak menjadi pemicu pada naik turunnya harga saham. Hal ini dikarenakan investor bukan hanya melihat kemampuan internal perusahaan dalam mendapatkan keuntungan namun juga mengamati risiko luar dan keadaan pasar. Risiko yang di luar pengendalian perusahaan seperti naiknya tarif, inflasi, berubahnya kebijakan pemerintah mengenai ekonomi dan politik. Supply dan demand di pasar modal juga menjadi alasan sebagai pengambilan keputusan investasi, sehingga bisa memicu fluktuasi pada harga saham. Riset ini sesuai dengan riset (Egam et al., 2017) yang menyebutkan bahwasanya ROA tidak mempengaruhi harga saham. 


\subsubsection{Pengaruh Earning Per Share Terhadap Harga Saham}

Hasil riset memperlihatkan bahwasanya EPS berpengaruh signifikan pada harga saham dapat dilihat pada tabel di atas yang memperlihatkan bahwasanya nilai signikansi sebesar $0,000<0,05$ serta nilai koefisien 15,009. Riset sesuai dengan riset (Egam et al., 2017) yang menyebutkan bahwa EPS mempengaruhi signifikan pada harga saham.EPS menunjukkan profitabilitas perusahaan secara nyata dengan melihat nilainya pada perlembar saham. EPS mampu mempengaruhi secara positif. Nilai EPS yang tinggi, mampu memicu daya tarik investor untuk berinvestasi, hal itu disebabkan bahwa makin besar laba yang diperoleh pemegang saham maka dapat meningkatan jumlah dividen.

\section{Kesimpulan, Keterbatasan, dan Saran}

Berlandaskan hasil riset pada uji hipotesis, bisa disimpulkan bahwasanya harga saham mampu dipengaruhi secara signifikan oleh variabel ROE dan EPS. Harga saham tidak terpangaruh signifikan oleh variabel rasio free float dan ROA.

Riset ini hanya menggunakan empat variabel independen, disarankan bagi peneliti selanjutnya menambah dan mengganti variabel independen lain yang diperkirakan bisa mempengaruhi harga saham yang tidak diuji dalam kajian ini. Penelitian hanya memakai objek Indeks LQ45 yang terdaftar di Bursa Efek Indonesia, sehingga sampel penelitian yang dipakai masih sedikit dan penelitian, disarakan untuk peneliti selanjutnya agar memperluas populasi serta sampel penelitian.

\section{Daftar Pustaka}

Bansal, R. (2014). A Comparative Analysis of the Financial Ratios of Selected Banks in the India for the period of 2011-2014. Research Journal of Finance and Accounting, 5(19), 153-168.

Bodie, K. dan M. (2014). Manajemen Portofolio dan Investasi (Investment) (9 JILID 2). Salemba Empat.

Bostanci, F., \& Kilic, S. (2010). The Effects of Rasio free floats on Market Performance: an Empirical Study on the Istanbul Stock Exchange. Istanbul Stock Exchange Review, 12(45), $1-25$.

Darmadji, T. dan H. M. F. (2011). Pasar Modal di Indonesia (KETIGA). Salemba Empat.

Dendawijaya, L. (2013). Manajemen Pebankan. GHALIA INDONESIA.

Egam, G. E. Y., llat, V., \& Pangerapan, S. (2017). PENGARUH RETURN ON ASSET (ROA), RETURN ON EQUITY (ROE), NET PROFIT MARGIN (NPM), DAN EARNING PER SHARE (EPS) TERHADAP HARGA SAHAM PERUSAHAAN YANG TERGABUNG DALAM INDEKS LQ45 DI BURSA EFEK INDONESIA PERIODE TAHUN 2013-2015. Jurnal EMBA: Jurnal Riset Ekonomi, Manajemen, Bisnis Dan Akuntansi, 5.

Fahmi, I. (2012). pengantar pasar modal. Alfabeta. 
Ghozali, I. (2016). ibm spss (7th ed.). universitas diponegoro.

Hery. (2015). Analisis Laporan Keuangan. CAPS.

Husnan, S. (2015). Dasar-dasar Teori Portofolio dan Analisis Sekuritas (keempat). BPFE.

Ira Roshita Dewi, A., \& Sri Artini, L. (2016). Pengaruh Suku Bunga Sbi, Inflasi, Dan Fundamenal Perusahaan Terhadap Harga Saham Indeks Lq-45 Di Bei. E-Jurnal Manajemen Universitas Udayana, 5(4), 253314.

KAMSIR. (2013). ANALISIS LAPORAN KEUANGAN. PT. Raja Grafindo Persada.

Khairani, I. (2016). Pengaruh Earning Per Share (EPS) dan Deviden Per Share terhadap Harga Saham Perusahaan Pertambangan yang Terdaftar di Bursa Efek Indonesia (BEI) Tahun 2011-2013. Jurnal Manajemen Dan Keuangan Unsam, 5(2), 566-572.

MUSSALAMAH, A. D. M. (2017). PENGARUH EARNING PER SHARE (EPS), DEBT TO EQUITY RATIO (DER) DAN RETURN ON EQUITY (ROE) TERHADAP HARGA SAHAM (Studi Empiris Pada Perusahaan Manufaktur yang Terdaftar di Bursa Efek Indonesia Tahun 2007-2011).

Nino, Y., Murni, S., \& Tumiwa, J. R. (2016). Analisis Ukuran Perusahaan, Struktur Modal, Non Performing Loan (NPL), Capital Adequacy Ratio (CAR), dan Return On Equity (ROE) Terhadap Harga Saham Perusahaan Pada Indeks LQ45. Jurnal EMBA: Jurnal Riset Ekonomi, Manajemen, Bisnis Dan Akuntansi, 4(3), 717-728.

Noor, J. (2011). Metodologi Penelitian:Skripsi, Tesis, Disertasi dan Karya IImiah (Cetakan ke). Prenada Media Group.

Rahmadewi, P. W., \& Abundanti, N. (2018). Pengaruh Eps, Per, Cr Dan Roe Terhadap Harga Saham Di Bursa Efek Indonesia. E-Jurnal Manajemen Universitas Udayana, 7(4), 2106. https://doi.org/10.24843/ejmunud.2018.v07.i04.p14

Santy, V. A. D., \& Triyonowati. (2017). PENGARUH ROA, ROE, DAN EPS TERHADAP HARGA SAHAM PT. GARUDA INDONESIA Tbk. Jurnal IImu Dan Riset Manajemen, 6.

Subramanyam, K. R. (2017). Analisis Laporan Kuangan (11th ed.). Salemba Empat.

SUGIYONO. (2013). Metode Penelitian Bisnis (Cetakan Ke). Alfabeta.

Suwandi, E. D. (2020). Pengaruh Rasio Saham Free Float Terhadap Harga Saham Perusahaan LQ45 Yang Terdaftar Di BEI Pada Tahun 2019. Jurnal Kajian Ekonomi Dan Kebijakan Publik, 5.

Tandelilin, E. (2010). Analisis Investasi dan Manajemen Portofolio. BPFE.

Watung, R., \& llat, V. (2016). Pengaruh Return on Asset (Roa), Net Profit Margin (Npm), Dan Earning Per Share (Eps) Terhadap Harga Saham Pada Perusahaan Perbankan Di Bursa Efek Indonesia Periode 2011-2015. Jurnal Riset Ekonomi, Manajemen, Bisnis Dan Akuntansi, 4(2), 518-529. https://doi.org/10.35794/emba.v4i2.13108 